\title{
Phytochemical Evaluation, Anti-obesity and Antihyperlipidemic Effects of Combined Administration of Green Coffee, Cinnamon and Ginger
}

\author{
Gehan Fawzy Abdel Raoof ${ }^{1, *}$, Khaled Younes Mohamed², Hala Mahmoud Mohammed ${ }^{3}$ \\ ${ }^{1}$ Pharmacognosy Department, National Research Centre, Giza, Egypt \\ ${ }^{2}$ Internal Medicine Department, National Research Centre, Giza, Egypt \\ ${ }^{3}$ Food Industry Department, Faculty of Agriculture, Cairo University, Cairo, Egypt
}

Email address:

ahmedkhaled_1@hotmail.com (G. F. A. Raoof), gehankandee19@yahoo.com (G. F. A. Raoof)

${ }^{*}$ Corresponding author

\section{To cite this article:}

Gehan Fawzy Abdel Raoof, Khaled Younes Mohamed, Hala Mahmoud Mohammed. Phytochemical Evaluation, Anti-obesity and Antihyperlipidemic Effects of Combined Administration of Green Coffee, Cinnamon and Ginger. Plant. Vol. 5, No. 5, 2017 , pp. 80-84. doi: 10.11648/j.plant.20170505.12

Received: October 8, 2017; Accepted: October 18, 2017; Published: November 8, 2017

\begin{abstract}
This study aims to evaluate anti-obesity and antihyperlipidemic effects of individual and combined administration of ginger, cinnamon and green coffee on the hyperlipidimic rats. It is the first report dealing with the effects of the combined administration of these three plants as anti-obesity and antihyperlipidemic agents. Sprague-Dawley rats were used, where they divided into 6 groups ( 7 rats each). Group 1 was kept as a normal control, while the other groups fed on high-fat diet to induce obesity and hyperlipidemia for 4 weeks. Group 2 positive control that was kept obese, while other groups were orally given individual and combined powders of ginger, cinnamon and green coffee in doses $200 \mathrm{mg} / \mathrm{kg}$, respectively, for 6 weeks, At the end of the experiment, body weight of rats were recorded. Blood samples were collected for analyses. The results showed that each of individual and combined administration of these plants significantly $(\mathrm{P}<0.05)$ decreased the body weight and serum lipids including total lipid, triglyceride and low density lipoprotein when compared with positive control group, while they significantly $(\mathrm{P}<0.05)$ increased high density lipoprotein when compared with positive control group. Furthermore, our study showed that the combination of these three plants exhibited better effects than when compared to the individual powder of the plants. In this study we compared the effects of separated and combined administration of cinnamon bark, ginger root, green coffee beans as anti-obesity and antihyperlipidemic agents. The separated and combined administration exhibited significant anti-obesity and antihyperlipidemic effects in obese and hyperlipidemic rats, while the combined administration showed more powerful effects. Previous reports on cinnamon, ginger and green coffee as separately administered were thus confirmed; however, this is, to our knowledge, the first report dealing with the combined form of the three plants. Such combined administration might be useful in developing natural food additives to help address obesity and hyperlipidemia.
\end{abstract}

Keywords: Ginger, Cinnamon, Green Coffee, Lipid, Obesity

\section{Introduction}

Obesity is one of the most health problems worldwide [1]. Obesity leads to many of metabolic disorders such as inflammation-related pathologies, cardiovascular diseases, hypertension and diabetes mellitus [2]. A lifestyle modification and natural alternatives could be used instead of surgery and chemical drugs in treatment of the obesity to avoid their side effects [3]. More researches are required to produce anti-obesity drugs fromn atural source and focused on both efficacy and safety of these plants materials [3].

Cinnamomum zeylanicum L. (Cinnamon) family Lauraceae, is used in both European and Arabian countries as spice that is used to flavor most foods [4]. Cinnamon is used in folk medicine for its antidiabetic, antihyperlipidemic, antiobesity antioxidant and hepatoprotective activities [5-9]. Zingiber officinale (Ginger) family Zingiberaceae is used as a 
spice and it is used medicinally for its anti-obesity, antihyperlipidemic, antidiabetic, anti-oxidant and hepatoprotective effects [10-13].

Coffea Arabica (Green Coffee bean) family Rubiaceae showed potent antioxidant activity due to its constituents [14]. Recent studies showed that green coffee had antidiabetic, anti-obesity, antihyperlipidemic, antihypertensive [15-19]. These biological activities were found to be due to the presence of chlorogenic acids in green coffee [20].

Each one of these plants showed anti-obesity and antihyperlipidemic activities in many reports [7-18]. Nothing dealing with the combination of these three plants, so this study aims to compare between the effect of separated and combined administration of these plants as anti-obesity and antihyperlipidemic agents. In this work, we used these plants in the powdered form instead of extractedor formulated products as patients prefer to eat plants as spice and salad, as well as, they are usually more tolerated than extracted form. Therefore, objectives of this study were to evaluate the effect of combined administration of ginger root, cinnamon bark and green coffee beans powder as natural feed additives on obesity and hyperlipidemia.

\section{Materials and Methods}

\subsection{Plant Materials}

Dried Cinnamon barks (Cinnamomum zillanicum, family Lauraceae), ginger rhizomes (Zingiber officinale, family Zingiberaceae) and Green Coffee beans (Coffea arabica, family Rubiaceae) samples were obtained dry from Medicinal and Aromatic Plant Research Department, Horticulture Research Institute, Agriculture Research Centre, Giza, Egypt.

\subsection{Preparation of the Plants Extracts}

Dried: Ginger, Cinnamon and Green Coffee (500g each) were powdered by using laboratory mill before extraction, then the plants were extracted with ethanol (70\%) several times at room temperature by maceration method. Each extract was concentrated under reduced pressure to give $39 \mathrm{~g}$, $45.5 \mathrm{~g}$ and $54.5 \mathrm{~g}$, respectively.

\subsection{Phytochemical Screening}

Chemical tests were carried out on theme than olic extracts using standard procedure to identify the constituents as described by [21, 22].

\subsection{Total Phenolic Assay}

The total phenolic content (TP) was determined applying the Folin-Ciocalteu colorimetric method using gallic acid as a standard [23], and expressed as milligrams of gallic acid equivalents $(\mathrm{GAE}) / \mathrm{g}$ of the dry plant materials.

\subsection{Total Flavonoid Assay}

Total flavonoid content (TFC) was measured using an aluminum chloride colorimetric assay [24]. A calibration curve was established using quercetin as a standard. TFC was expressed as $\mathrm{mg}$ quercetin equivalent $(\mathrm{QE}) / \mathrm{g}$ of the dry plant materials.

\subsection{Biological Evaluation}

\subsubsection{Animals}

Forty-two adult male Sprague-Dawley rats weighing 200$210 \mathrm{~g}$ body weight (B.wt) and 10-12 weeks old were used in this study. Animals were obtained from Laboratory Animal Colony, Agricultural Research Center, Giza, Egypt. Rats were housed in a well-ventilated animal room under controlled hygienic conditions of $24^{\circ} \mathrm{C}$ temperature, $50 \%$ relative humidity and $12 \mathrm{~h}$ light $/ 12 \mathrm{~h}$ dark cycles. Basal diet and water were provided. The experiment on rats was carried out in accordance with the recommendations of the National regulations on animal welfare and Institutional Animal Ethical Committee (IAEC).

\subsubsection{Induction of Obesity}

Obesity and acute hyperlipidemia were induced by feeding rats on high-fat diet (HFD) which supplies $45 \%$ calories for 4 weeks. A3-4 weeks HFD feeding is sufficient to induce obesity [25].

\subsubsection{Experimental Design}

Forty-two mature male Sprague-Dawley rats were randomized into 6 groups of 7 rats each. Group 1 was negative (normal) control, and the other 5 groups were fed on hyperlipidemic diet to induce obesity and hyperlipidemia through the feeding period (4 weeks). Group 2 was kept obese (positive control) and groups 3,4 and 5 were orally given ginger, cinnamon and green coffee powder in doses $200 \mathrm{mg} / \mathrm{kg}$, respectively for 6 weeks, while groups 6 was given $200 \mathrm{mg} / \mathrm{kg}$ of the combined powder of the three plants in the ratio 20,30 and $50 \%$ ginger, cinnamon and green coffee, respectively, this ratio was based on the ratio of the phenolic contents of three plants that was recorded in this study. At the end of the experiment, B.wts of rats were recorded.

\subsubsection{Blood Sampling and Analysis}

Blood samples were collected after six weeks in tubes contain heparin as an anticoagulant from the eye plexuses under diethyl ether anesthesia and then centrifuged at $3000 \mathrm{rpm}$ for $20 \mathrm{~min}$. to obtain plasma, which was kept frozen until analysis. The total cholesterol was analyzed calorimetrically according to [26] method, triglycerides (TG) was determined according to [27], LDL-cholesterol was calculated according to [27], HDL-cholesterol was determined according to [26] method.

\subsubsection{Statistical Analysis}

Data were presented as means \pm standard error. Differences between control and treated groups were tested for significance using one-way analysis of variance followed by Duncan's multiple range test [28]. Statistical analysis was performed using computerized software program Statistical 
Package for Social Sciences version 15 (Chicago, IL606066412, USA).

\section{Results and Discussion}

\subsection{Phytochemical Analysis}

Phytochemical analysis of medicinal plants is very important in the evaluation of biologically active compounds. The results showed that tannins, terpenoids, flavonoids and alkaloids were present in cinnamon, ginger and green coffee, while saponins were absent in all samples under investigation. The phytochemicals of medicinal plants showed different biological activities, which play an important role in the protection against chronic diseases [29].

\subsection{Total Phenolic and Flavonoids Contents}

Table (1) showed that total phenolic content of ginger, cinnamon and green coffee were $(23.4,31.1$ and $49.3 \mathrm{mg}$ gallic acid equivalent $/ g$ of the dry plant materials, respectively), while the total flavonoid were $(16.5,22.7$ and $30.3 \mathrm{mg}$ quercetin equivalent $(\mathrm{QE}) / \mathrm{g}$ of the dry plant materials, respectively). Phenolic compounds of medicinal plants such as flavonoids, showed antioxidant activities [30]. Furthermore, the diet that contains high level of flavonoids could protect the human from many diseases [31].

Table 1. Total phenolic and flavonoids contents of cinnamon, ginger and green coffee.

\begin{tabular}{lll}
\hline Plant & Phenolic content $(\mathbf{m g} / \mathbf{g})$ & Flavonoids content $(\mathbf{m g} / \mathbf{g})$ \\
\hline Cinnamon & 31.1 & 22.7 \\
Ginger & 23.4 & 16.5 \\
Green coffee & 49.3 & 30.3 \\
\hline
\end{tabular}

\subsection{Anti-obesity and Antihyperlipidemic Activities}

Body weight (B.wt) significantly $(\mathrm{P}<0.05)$ increased in rats fed on high fat diet (HFD) for 4 weeks when compared to negative control (rats fed on the normal diet). Separated and combined administration of cinnamon, ginger and green coffee induced significant $(\mathrm{P}<0.05)$ decreases in B.wt compared to the positive control group when they were administrated to obese rats for 6 weeks. This effect was better in combined powder treated group than separated administration, as shown in Table 2.

Serum levels of LDL-C, TG and TC significantly $(\mathrm{P}<0.05)$ increases in rats fed on HFD for 4 weeks when compared to negative control rats. Oral administration of cinnamon, ginger and green coffee as well as well as their combination, to obese rats significantly $(\mathrm{P}<0.05)$ decreased the high levels of serum LDLC, TG and TC when compared with the positive control group. The results showed that the combined treatment showed more powerful effects than the separated administration (table 2).

Serum HDL-C significantly $(\mathrm{P}<0.05)$ decreased in rats fed on HFD for 4 weeks when compared to negative control rats. Oral administration of cinnamon, ginger and green coffee as well as well as their combination, to obese rats induced a significant $(\mathrm{P}<0.05)$ increase in serum $\mathrm{HDL}$ and when compared with the positive control groups. The result showed that this effect was better in combined powder treated group than the separated administration (Table 2).

So our results showed that each one of these plants is effective in the decreasing of serum lipids and body weight, these effects agreed with the previous studies which also stated that the activities were due to the phenolic contents reported in these plants [7-18]. Moreover, previous studies showed that the combination of cinnamon and ginger was effective as anti-obesity and antihyperlipidemic agent [32, 33]. Nothing dealing with the combination of these three plants, so, our study showed for the firs time, that the combination of these three plants exhibited more powerful effects than that of individual powder of the plants and more than that reported for the combined cinnamon and ginger [32, 33]. It can be suggested that the synergistic effect of the phenolic contents of these plants may play an important role in showing these powerful effects. The present study suggests that the combined powder had synergetic antiobesity and antihyperlipidemic activities by decreasing body weight and serum lipid levels and therefore attribute to therapeutic value of the combined plant powder of ginger, cinnamom and green coffee to combat the obesity and hyperlipidemia in rats. Further, combination of the isolated active ingredients from these plants may be a subject of interest in the future for management of obesity and hyperlipidemia.

Table 2. The effect of cinnamon, ginger, green coffee and their combination on body weight and lipid profile.

\begin{tabular}{llllll}
\hline Groups & B.wt $(\mathbf{g})$ & TC(mg/dl) & TG(mg/dl) & LDL-C(mg/dl) & HDL-C(mg/dl) \\
\hline Normal control & $243.0 \pm 3.2$ & $79 \pm 2.0$ & $85.06 \pm 1.4$ & $32.05 \pm 1.9$ & $30.03 \pm 1.4$ \\
Positive control & $313.0 \pm 5.4^{\mathrm{a}}$ & $89 \pm 3.03^{\mathrm{a}}$ & $98.07 \pm 1.6^{\mathrm{a}}$ & $45.12 \pm 2.0^{\mathrm{a}}$ & $26.10 \pm 1.1^{\mathrm{a}}$ \\
Ginger treatment group & $282.0 \pm 3.5^{\mathrm{b}}$ & $82.03 \pm 2.1^{\mathrm{b}}$ & $92.12 \pm 3.6$ & $38.07 \pm 2.1^{\mathrm{b}}$ & $27.31 \pm 1.6^{\mathrm{b}}$ \\
Cinnamon treatment group & $275.0 \pm 2.4^{\mathrm{ab}}$ & $80.12 \pm 1.4^{\mathrm{b}}$ & $89.23 \pm 2.9^{\mathrm{ab}}$ & $36.26 \pm 2.8^{\mathrm{ab}}$ & $29.37 \pm 1.9^{\mathrm{ab}}$ \\
Green coffee treatment group & $267.0 \pm 1.9^{\mathrm{ab}}$ & $79.28 \pm 3.9^{\mathrm{b}}$ & $87.81 \pm 2.2^{\mathrm{ab}}$ & $34.12 \pm 2.3^{\mathrm{ab}}$ & $32.07 \pm 3.1^{\mathrm{ab}}$ \\
Combined treatment group & $247.0 \pm 1.2^{\mathrm{ab}}$ & $78.13 \pm 1.2^{\mathrm{ab}}$ & $85.31 \pm 1.2^{\mathrm{ab}}$ & $32.15 \pm 1.6^{\mathrm{ab}}$ & $38.23 \pm 2.5^{\mathrm{ab}}$ \\
\hline
\end{tabular}

One-way ANOVA test, significant at P-value $<0.05$; ${ }^{\mathrm{a}}$ compared to normal control group, ${ }^{\mathrm{b}}$ compared to positive control group. B.wt: body weight, TC: total cholesterol, TG: triglycerides, LDL-C: low density lipoprotein cholesterol, HDL-C: high density lipoprotein cholesterol.

\section{Conclusion}

This study aims to compare between the effect of separated and combined administration of cinnamon bark, ginger root, green coffee beans as anti-obesity and antihyperlipidemic agents. The separated and combined administration exhibit 
significant anti-obesity and antihyperlipidemic effects in obese and hyperlipidemic rats, while the combined administration showed more powerful effects. These effects confirm the previous reports on cinnamon, ginger and green coffee as separated administration but it is the first report dealing with the combined form of the three plants. Therefore, objectives of this study were to evaluate the effect of combined administration of these plants as natural feed additives on obesity and hyperlipidemia.

\section{Conflicts of Interest}

The authors declare that they have no competing interests

\section{Acknowledgements}

We acknowledge to National Research Centre and Faculty of Agriculture, Cairo University for using laboratory instruments in doing research.

\section{References}

[1] Power M. L., Schulkin J. Sex differences in fat storage, fat metabolism, and the health risks from obesity: Possible evolutionary origins, Br J Nutr, 99(2008) 931-40.

[2] Hotamisligil G. S., Erbay E. Nutrient sens in gand inflammation in metabolic diseases. Nat Rev Immunol, 8(2008) 923-34.

[3] Devendra D., Liu E., Eisenbarth G. S. Type 1 diabetes: Recent developments. BMJ, 328(2004) 750-754.

[4] Qin B., Nagasaki M., Ren M., Bajotto G., Oshida Y., Sato Y. Cinnamon extract (traditional herb) potentiates in vivo insulinregulated glucose utilization via enhancing insulin signal in ginrats. Diabetes Res Clin Pract, 62: 1(2003) 39-48.

[5] Moselhy S. S, Ali H. K. Hepatoprotective effect of cinnamon extracts against carbon tetrachloride induced oxidative stress and liver injury in rats. Biol Res, 42(2009)93-8.

[6] Azab K. S. h., Mostafa A. H., Ali E. M., Abdel-Aziz M. A. Cinnamon extract ameliorates ionizing gradiation-induced cellular injury in rats. Ecotoxicol Environ Saf, 74(2011) 2324-9.

[7] Vafa M., Mohammadi F., Shidfar F., Sormaghi M. S., HeidariI., Golestan B., et al. Effects of cinnamon consumption on glycemic status, lipid profile and body composition in type 2 diabetic patients. Int J Prev Med, 3(2012) 531-6.

[8] Shatwan I. A., Ahmed L. A., Badkook M. M. Effect of barley flour, crude cinnamon, and their combination on glycemia, dyslipidemia, and adipose tissue hormones in type 2 diabeticrats. J Med Food, 16(2013) 656-62.

[9] Lee S. C., Xu W. X., Lin L. Y., Yang J. J., Liu C. T. Chemical composition and hypoglycemic and pancreas-protective effect of leaf essential oil from indigenous cinnamon (Cinnamomum osmophloeum Kanehira). J Agric Food Chem, 61(2013) 490513.

[10] Abdel-Azeem A. S., Hegazy A. M., Ibrahim K. S., Farrag A. R., El-Sayed E. M. Hepatoprotective, antioxidant, and ameliorative effects of ginger (Zingiber officinale Roscoe) and vitamin E in acetaminophen treated rats. J Diet Suppl, 10(2013) 195-209.

[11] Akhani S. P., Vishwakarma S. L., Goyal R. K. Anti-diabetic activity of Zingiber officinale in streptozotocin-induced type I diabetic rats. J Pharm Pharmacol, 56(2004) 101-5.

[12] El Rokhel-SM., Yassin N. A, El-Shenawy S. M., Ibrahim B. M. Antihypercholesterolaemic effect of ginger rhizome (Zingibero fficinale) in rats. Inflammopharmacology 1 8(2010) 309-15.

[13] Mahmoud R. H, Elnour W. A. Comparative evaluation of the efficacy of ginger and orlistat on obesity management, pancreatic lipase and liver peroxisomal catalase enzyme in male albino rats. Eur Rev Med Pharmacol Sci, 17(2013)7 583.

[14] Suzuki A., Kagawa D., Ochiai R., Tokimitsu I., Saito I. Green coffee bean extract and its metabolite shaveahy potensive effect in spontaneously hypertensive rats. Hypertens Res, 25(2002) 99-107.

[15] Kozuma K., Tsuchiya S., Kohori J., Hase T., Tokimitsu I. Antihypertensive effect of green coffee bean extract on mildly hypertensive subjects. Hypertens Res. 28(2005) 711-8.

[16] Ochiai R., Jokura H., Suzuki A., Tokimitsu I., Ohishi M., Komai N., Rakugi H., Ogihara T. Green coffee bean extract improves human vaso reactivity. Hypertens Res. 27(2004) 731-7.

[17] Shimoda H., Seki E., Aitani M. Inhibitory effect of green coffee bean extract on fat accumulation and body weight gain in mice. BMC Complement Altern Med. 6(2006) 1-9.

[18] Dellalibera O., Lemaire B., Lafay S. Le Svetol, un extrait de cafe' vert de' cafe' ine', induit une perte depoids et augument le ratio mass emaigre sur masse grasse chez des volontaires en surcharge ponde' rale. Phytotherapie. 4(2006) 1-4.

[19] Blum J., Lemaire B., Lafay S. Effect of a green decaffeinated coffee extract on glycaemia. Nutra Foods Res. 6(2007) 13-7.

[20] Farah A., De Paulis T., Trugo L. C., Martin P. R. Effect of roasting on the formation of chlorogenic acid lactones in coffee. J Agric Food Chem. 53(2005) 1505-13.

[21] Harbone J. B. Phytochemical methods. London: Chapman and Hall, Ltd.; 1973, pp 49.

[22] Sofowora A. Medicinal plants and Traditional medicine in Africa. Ibadan, Ibadan, Nigeria: Spectrum Books Ltd; 1993, pp 289.

[23] Siger A., Nogala-Kalucka M., Lampart-Szczapa E. The content and antioxidant activity of phenolics compounds in cold-pressed plantoils. J Food Lipids 15(2008) 137-149.

[24] Zhishen J., Mengcheng T., Jianming W. The determination of flavonoid contents in mulberry and their scavenging effects on superoxide radicals. Food Chem 64(1999) 555-559.

[25] Bhatt B. A., Dube JJ., Dedousis N., Reider J. A., O'Doherty RM. Dietinduced obesity and acute hyperlipidemia reduce Ikappa B alpha levels in rat skeletal muscle in a fiber-type dependent manner. Am J Physiol Regul Integr Comp Physiol 290(2006) R233-40.

[26] Richmond N. Colorimetric determination of total cholesterol and high density lipoprotein cholesterol (HDL). Clin Chem 19(1973) 1350-6. 
[27] Friedewald W. T., Levy R. I., Fredrickson D. S. Estimation of the concentration of low-density lipoprotein cholesterol in plasma, without use of the preparative ultra centrifuge. Clin Chem 18(1972) 499-502.

[28] Snedecor G. W., Cochran W. G. Statistical Methods. $7^{\text {th }}$ ed. Ames, USA: Iowa State University Press; 1986. pp. 90-9.

[29] Oloyed OI. Chemical profile of unripe pulp of Carica pagaya. Pak J Nutr, 4(2005) 379-381.

[30] Van Acker S. A., Van Den Berg D. J., Tromp MN., Griffioen DH., Van Bennekom WP., Vander Vijgh WJ. Structural aspects of antioxidant activity of flavanoids. Free Radical Bio Med 20(3), (1996) 331-342.
[31] Hertog M. L., Feskens E. J., Hollman PH., Katan MB., Kromhout D. Dietary antioxidants flavonoids and the risk of coronary heart disease: the zutphen elderly study. Lancet, 342(1993) 1007-1011.

[32] Mostafa AS., Hamed YS. Some pharmacological effects of cinnamon and ginger herbs in obese diabeticrats. $J$ Intercult Ethnopharmacol, 3(4) (2014) 144-149.

[33] Salah M., and Reham A. Effect of Combined Administration of Ginger and Cinnamon on High Fat Diet induced Hyperlipidemia in Rats. J. Pharm Chem Biol Sci, 3(4) (2016) 561-572. 